\title{
INFLUENCE OF OXIDATIVE STRESS AND OBESITY IN PATIENTS WITH NONALCOHOLIC STEATOHEPATITIS
}

\author{
Gabriela Esteves LEGHI ${ }^{1}$, Fernanda Aparecida DOMENICI ${ }^{2}$ and Helio VANNUCCHI ${ }^{3}$
}

Received 24/3/2015

\begin{abstract}
Background - Nonalcoholic steatohepatitis is considered the hepatic manifestation of metabolic syndrome and it is particularly associated to the insulin resistance, hypertension, obesity and abnormalities in lipid and glucose metabolism. Objective Considering the importance of obesity and oxidative stress in the pathophysiology of nonalcoholic steatohepatitis, this study aimed to evaluate the presence and association of the obesity and oxidative stress in this pathology. Methods - Fifteen outpatients with nonalcoholic steatohepatitis (nonalcoholic steatohepatitis group), diagnosed according to the histopathological findings from the liver biopsy, and 15 body mass index-matched subjects (non nonalcoholic steatohepatitis group) without nonalcoholic steatohepatitis were included. All volunteers were registered in a Brazilian University Hospital. Nutritional assessment (weight, height, body mass index and waist circumference) and biochemical analysis (fasting glucose, liver enzymes, lipid profile, leptin, superoxide dismutase, glutathione peroxidase, vitamins $\mathrm{C}$ and $\mathrm{E}$, catalase and 8-isoprostane) were performed for all the participants. The student $\mathrm{t}$ test was used for statistical analysis, with $P<0.05$ as the significant factor. Results - Nonalcoholic steatohepatitis patients had higher fasting glucose, hepatic enzymes (serum aspartate aminotransaminase, alanine aminotransaminase, gamma glutamyl transferase, alkaline phosphatase), triglycerides and superoxide dismutase and lower glutathione peroxidase values than non nonalcoholic steatohepatitis individuals. Conclusion - This paper demonstrates that only the presence of obesity is not enough to trigger alterations in all the studied biomarkers. Despite the majority of oxidative stress markers being found to be similar in both conditions, the nonalcoholic steatohepatitis subjects could be slightly more affected than the non nonalcoholic steatohepatitis individuals
\end{abstract}

HEADINGS - Non-alcoholic fatty liver disease. Obesity. Metabolic syndrome x. Oxidative stress. Biological markers.

\section{INTRODUCTION}

Non-alcoholic fatty liver disease (NAFLD) is known to be a significant cause of morbidity in developed countries ${ }^{(25)}$. Its prevalence ranges from $10 \%$ to $24 \%$ in the general population and reaches $75 \%$ in groups of obese patients ${ }^{(8)}$. NAFLD includes cases of pure steatosis to more severe conditions such as nonalcoholic steatohepatites (NASH) and cirrhosis ${ }^{(25)}$. Also, available data in the literature suggest that NASH is progressive, leading to a significant morbidity ${ }^{(4)}$.

The incidence of pure steatotis and NASH have increased in parallel with the obesity epidemy which currently affects around $2 / 3$ of the American population $^{(36)}$. About 40 million American adults are estimated to have hepatic steatosis or NASH, 58\%-74\% of this being obese ${ }^{(3)}$.
NASH is considered the hepatic manifestation of metabolic syndrome (MetS) and is particularly associated with insulin resistance, hypertension, obesity and abnormalities in lipid and glucose metabolism ${ }^{(30)}$. Nutritional factors are commonly related to $\mathrm{NASH}$, such as obesity, dyslipidemia, type 2 diabetes melittus (T2DM), malnutrition, extensive intestinal ressection and oversupply of non-proteic calories. The adipose tissue plays a key role in the occurrence of hepatic complications and they may have a strong association between these tissues, being related to the NASH development ${ }^{(12)}$. NASH is considered from an unknown cause when it is not possible to identify its risk factors ${ }^{(3)}$.

Currently, the pathogenesis of NASH has been explained by the "multi-hit" hypothesis which it is based on two proposed mechanisms ${ }^{(12)}$. The insulin re-

Declared conflict of interest of all authors: none

Disclosure of funding: Financial support from Fapesp (Fundação de Amparo à Pesquisa do Estado de São Paulo)

${ }^{1}$ Divisão de Nutrição Clínica, Departamento de Medicina Interna, Faculdade de Medicina de Ribeirão Preto, Universidade de São Paulo; ${ }^{2}$ Divisão de Gastroenterologia Departamento de Medicine Interna, Faculdade de Medicina de Ribeirão Preto, Universidade de São Paulo; ${ }^{3}$ Departamento de Patologia e Medicina Legal, Faculdade de Medicina de Ribeirão Preto, Universidade de São Paulo, Brasil.

Correspondence: Gabriela Esteves Leghi. Rua Joaquim Procópio de Araújo, 2809, Centro - CEP: 13631-020 - Pirassununga, SP, Brasil. E-mail: gabi_leghi@hotmail.com 
sistance, attributed to the first hit, increases the vulnerability of the liver to injury, leading to the steatosis ${ }^{(1)}$. The second hit is responsible for the inflammation, steatohepatitis or fibrosis and apoptosis, and it can also include oxidative stress (OS) with liver lipid peroxidation, cytokines or proinflammatory adipokines and mitochondrial dysfunction. High levels of OS can reduce the ability of mature hepatocytes to proliferate, resulting in decreased endogenous repair ${ }^{(39)}$.

There are cellular mechanisms responsible for OS control which are extremely important to the cell homeostasis through the antioxidants system which can control the formation of reactive oxygen species (ROS) or reactive nitrogen species (RNS) and also repair oxidative damage to cells. The antioxidants can derive from the diet or endogenous mechanisms which are divided into enzymatic superoxide dismutase (SOD), catalase and glutathione peroxidase (GPx), for example) and non-enzymatics, such as glutathione and vitamins $^{(20)}$.

Oxidative stress appears in many diseases, particularly in those with an inflammatory nature, emphasizing the relationship between the obesity and liver diseases ${ }^{(45)}$. Several hepatic diseases feature high levels of ROS and RNS which represents a direct association with the severity and progression of these diseases ${ }^{(32,41)}$. Studies conducted in humans and animal models showed a strong association between the level of OS and the severity of $\mathrm{NASH}^{(39)}$. Although clinical and experimental studies have shown higher levels of lipid peroxidation in NASH patients, the antioxidants circulating levels remain not well investigated in these patients ${ }^{(2)}$.

The interaction between OS and cytokines has been closely related to the pathogenic mecanisms in NAFLD ${ }^{(42)}$. Leptin, an anorexigenic hormone with a proinflammatory role, is increased in obesity and considered a key mediator of liver fibrosis ${ }^{(45)}$. Products from the lipid peroxidation, such as $\mathrm{F}_{2}$ isoprostanes, are also related to inflammation and development of fibrosis ${ }^{(9)}$. 8-Isoprostane is considered as an important biomarker for lipid peroxidation ${ }^{(16)}$.

Recently, there has been no therapy with proven efficacy for NAFLD/NASH and the current treatment is associated to the metabolic profile, since the intervention in the lifestyle has mostly been used ${ }^{(35)}$. Therefore, a rigorous search for risk factors and environmental exposures that may increase the risk of developing NASH and its transition to more severe stages is essential ${ }^{(26)}$. Considering the importance of the obesity and OS in the appearance and progression of NASH, this study aimed to evaluate the presence and association of the obesity and OS in this pathology.

\section{METHODS}

\section{Subjects}

This case-control study included 15 outpatients with NASH (NASH group), diagnosed according to the histopathological findings from the liver biopsy. The group without NASH (Non-NASH group) consisted of 15 overweight subjects diagnosed according to normal liver ultrasound and the absence of laboratorial signs of hepatitis and other liver dysfunctions. Individuals from both genders aged 18-70 years old were selected; and to be eligible, they were required to have a BMI within the range of classification of overweight and obese $\left(>24.9 \mathrm{~kg} / \mathrm{m}^{2}\right)$. All volunteers were registered in a Brazilian University Hospital and provided informed consent according to the Institutional Research Ethics Committee (Proc\#15823/2011).

\section{Liver histology}

The grading and staging of all liver biopsy specimens were conducted by a pathologist specialized in hepatology. Liver samples were stained with hematoxylin and eosin, silver reticulin, Perls' for iron and Masson's trichrome for the assessment of liver fibrosis. The presence of more than 5\% steatotic hepatocytes in a liver tissue section was accepted as the minimum criterion for the histological diagnosis of NAFLD. The NASH histological grading and staging followed Brunt's criteria ${ }^{(7)}$.

\section{Biochemical analysis}

Venous blood samples were obtained after a 12-hours overnight fast. Plasma glucose, hepatic enzymes serum aspartate aminotransaminase (AST), alanine aminotransaminase (ALT), gamma glutamyl transferase (GGT), alkaline phosphatase), triglycerides, total and HDL-cholesterol were measured in a conventional automated analyzer. Low-density lipoprotein cholesterol (LDL-c) was calculated according to the equation of Friedewald et al. ${ }^{(15)}$. SOD activity was measured with a commercially available kit $\left(\text { RANDOX }^{\circledR}\right)^{(31)}$ and the GPx activity was determined according to Flohe \& Guntzler ${ }^{(14)}$. Catalase activity was determined by commercially available kit $\left(\right.$ Merck $\left.^{\circledR}\right)$, using a colorimetric method with the reading in a spectrophotometer at $540 \mathrm{~nm}$ filter ${ }^{(19)}$. Serum leptin and 8-isoprostane levels were measured using enzyme linked immunosorbent assays (Millipore ${ }^{\circledR}$ and $R \& D^{\circledR}$, respectively) following the manufacturer's instructions. The vitamins $\mathrm{C}$ and $\mathrm{E}$ analyses were performed by High-performance liquid chromatography (HPLC- SPD $20 \mathrm{~A})$ according to Rose $\&$ Bode $^{(40)}$ and Arnauld et al. ${ }^{(5)}$, respectively.

\section{Nutritional assessment}

The subjects weight and height were measured with standard techniques. The body mass index (BMI) was calculated by the formula: body weight $(\mathrm{kg}) /[\text { height }(\mathrm{m})]^{2}$. The waist circumference (WC) was at the midpoint between the lower border of the rib cage and the iliac crest ${ }^{(10)}$.

\section{Statistical analysis}

Statistical analysis was performed using the software GRAPHPAD PRISM 6.02. The Shapiro-Wilks test was used in order to determine a normal distribution from all data. The comparison of the numerical variables with the normal distribution between NASH and Non-NASH Groups was performed by the parametric test, Student $t$ test, and the variables were presented as mean and standard deviation. The level of significance was set at $P<0.05$. 


\section{RESULTS}

Demographic and anthropometric features of evaluated groups are available in Table 1. There were no statistical differences in the anthropometric values (weight, BMI and WC) between NASH and Non-NASH Groups, since both included overweight and obese individuals.

Laboratory data are presented in Table 2 . The NASH Group showed significantly $(P>0.05)$ higher levels of plasma glucose, AST, ALT, GGT, alkaline phosphatase and triglycerides. The high values of standard deviation from some hepatic enzymes, like GGT, could indicate that some NASH individuals might be in advanced stages of liver disease.

The oxidative stress values are shown in Table 3 . The

TABLE 1. Demographic and anthropometric features of groups

\begin{tabular}{lcc}
\hline & $\begin{array}{c}\text { NASH } \\
(\mathrm{n}=15)\end{array}$ & $\begin{array}{c}\text { Non-NASH } \\
(\mathrm{n}=15)\end{array}$ \\
\hline Age (years) & $50.5 \pm 2.9$ & $45.1 \pm 3.1$ \\
Female $(\%)$ & $10(66.7 \%)$ & $12(80 \%)$ \\
Male $(\%)$ & $5(33.3 \%)$ & $3(20 \%)$ \\
Weight $(\mathrm{kg})$ & $85.7 \pm 4.1$ & $81.7 \pm 4.4$ \\
Height $(\mathrm{m})$ & $1.6 \pm 0.1$ & $1.6 \pm 0.1$ \\
BMI $\left(\mathrm{kg} / \mathrm{m}^{2}\right)$ & $32.0 \pm 4.4$ & $30.4 \pm 4.1$ \\
WC $(\mathrm{cm})$ & $108.5 \pm 10.4$ & $100.3 \pm 12.1$ \\
\hline
\end{tabular}

$* P$ values $<0.05$. WC: waist circumference.

TABLE 2. Laboratorial data according to groups

\begin{tabular}{lll}
\hline & NASH & Non-NASH \\
\hline AST (U/L) & $49.5 \pm 36.7 *$ & $19.1 \pm 6.7$ \\
ALT (U/L) & $84.2 \pm 108.5^{*}$ & $21.7 \pm 11.7$ \\
GGT (U/L) & $246.5 \pm 530.4^{*}$ & $33.1 \pm 22.5$ \\
Alkaline phosphatase (U/L) & $239.1 \pm 143.0^{*}$ & $170.0 \pm 50.1$ \\
Triglycerides (mg/dL) & $165.9 \pm 50.4^{*}$ & $112.0 \pm 55.0$ \\
Total cholesterol (mg/dL) & $193.3 \pm 30.3$ & $178.8 \pm 36.1$ \\
LDL-cholesterol (mg/dL) & $118.0 \pm 25.8$ & $111.6 \pm 32.6$ \\
HDL-cholesterol (mg/dL) & $38.4 \pm 8.5$ & $44.9 \pm 12.2$ \\
Plasma glucose (mg/dL) & $96.7 \pm 19.6 *$ & $82.8 \pm 10.4$ \\
Leptin (ng/mL) & $16.6 \pm 10.7$ & $16.0 \pm 8.5$ \\
\hline
\end{tabular}

$* P$ values $<0.05$. AST: serum aspartate aminotransaminase; ALT: alanine aminotransaminase; GGT: gamma glutamyl transferase.

TABLE 3. Oxidative stress according to groups

\begin{tabular}{lcc}
\hline & NASH & Non-NASH \\
\hline SOD $(\mathrm{USOD} / \mathrm{g} \mathrm{Hb})$ & $1627.0 \pm 237.4^{*}$ & $1406.0 \pm 230.4$ \\
GPx $(\mathrm{umol} / \mathrm{min} / \mathrm{g} \mathrm{Hb})$ & $49.4 \pm 1.6$ & $59.0 \pm 2.0^{*}$ \\
Vitamin C $(\mathrm{mg} \%)$ & $0.2 \pm 0.1$ & $0.2 \pm 0.1$ \\
Vitamin E $(\mu \mathrm{mol} / \mathrm{L})$ & $26.5 \pm 8.0$ & $24.3 \pm 7.9$ \\
Catalase $(\mathrm{U} / \mathrm{gHb})$ & $124.7 \pm 30.1$ & $120.9 \pm 43.7$ \\
8 - isoprostane $(\mathrm{pg} / \mathrm{mL})$ & $29.3 \pm 16.3$ & $22.8 \pm 13.1$ \\
\hline
\end{tabular}

$* P$ values $<0.05$. SOD: superoxide dismutase; GPx: glutathione peroxidase.
NASH subjects presented significantly $(P>0.05)$ higher levels of SOD and the Non-NASH Group showed significantly $(P>0.05)$ higher levels of GPx when the groups were compared. There were no statistical differences in the other parameters.

\section{DISCUSSION}

In the present study, subjects from the NASH Group showed significantly $(P>0.05)$ higher levels of plasma glucose, AST, ALT, GGT, alkaline phosphatase and triglycerides than the Non-NASH Group. In other words, these biochemical markers are often more pronounced in the presence of a metabolic disorder caused by liver disease than just by obesity, since these are factors closely related to the pathophysiology of NASH.

Younossi et al. ${ }^{(48)}$ have found similar results in relation to the ALT and AST values however, they found no significant difference in plasma glucose, despite the NASH individuals have shown higher rates of T2DM $(36 \%)$ than the NonNASH Group (13\%). Regarding the lipid profile, the authors only found a significant increase in the total cholesterol levels in the Non-NASH subjects ${ }^{(48)}$

In concurrence with this paper, previous studies have also reported an increase of the hepatic enzymes ALT, AST ${ }^{(27,28)}$, alkaline phosphatase and GGT in NAFLD ${ }^{(24)}$. The levels of alkaline phosphatase and GGT are usually found high in NASH. There are a few literature discussions about the GGT and its frequence and rising rate, which can explain the presence of high standard deviation values in NASH Group ${ }^{(24)}$.

Marchesini et al. ${ }^{(30)}$ reported alterations in the glucose metabolism, including T2DM, glucose intolerance and hyperglycemia, which were associated to NASH. Published studies have both presented cases with significant differences in blood glucose levels between NAFLD and Control Groups ${ }^{(34)}$ and with no significant difference in these Groups as well ${ }^{(38,49)}$. Some authors have discussed the alterations in glucose metabolism as a risk factor to the development of NASH and its deterioration in the presence of obesity ${ }^{(30)}$.

Earlier observations in NAFLD patients showed that dyslipidemia was present in 20\%-92\% of the patients ${ }^{(11)}$. Zimmermann et al. ${ }^{(49)}$ evaluated the lipid profile of 37 patients with MetS, classifying them in NASH and Non-NASH Groups. There was no significant difference in the levels of total cholesterol, LDL and HDL between the two groups, strengthening the association between overweight/obesity and NASH. Also, patients with NASH often use medication to control the dyslipidemia, therefore, they may have normalized levels of cholesterol. The lipid profile alterations in NASH and obese patients have shown controversial findings in the literature, associating how close these two conditions are.

The serum leptin didn't have a statistical difference between the studied groups, suggesting the role of obesity as a major determinant in this indicator, regardless of the presence or absence of NASH. Previous papers have reported distint outcomes in the NASH Group, some showing positive association with increased levels of this hormone ${ }^{(17,43)}$, while 
others don't show this association ${ }^{(28,33)}$. Since leptin is an adipokine expressed exclusively in the adipose tissue and its levels associate positively with the percentage of body fat and $\mathrm{BMI}^{(43)}$; studies have shown that obese individuals have higher serum leptin levels than normal-weight individuals ${ }^{(18,44)}$.

Studies in humans and in experimental models have investigated the association between the presence of NASH and the level of oxidative stress, but as the control group generally is not composed by subjects metabolically compatible with the patients, it is difficult to establish a more accurate comparison between the groups. The present study has found similar levels of oxidative stress between the groups, except for higher levels of SOD and lower levels of GPx in NASH individuals. The other biomarkers showed no statistical difference. As these findings are based on the comparison of BMI-matched subjects, the literature remains controversial in regards to most of these results, since all available studies have only shown comparisons with eutrophic individuals. Furthermore, authors have discussed this lack of weight and BMI equivalency among patients with NASH or pure steatosis and healthy controls as a feasible limitation in the papers ${ }^{(17)}$.

In contrast to the presented result, authors have found lower levels of SOD in the NAFLD Group, when compared to Control Group in animals ${ }^{(2)}$ and in patients ${ }^{(47)}$. Das et al. ${ }^{(11)}$ have reported higher levels of SOD in individuals with NAFLD and Perlemuter et al. ${ }^{(37)}$ have found no difference in the activity of this enzyme. One likely explanation for the reported increase could be that the excessive generation of superoxide radical is an adaptive response to oxidative stress ${ }^{(23)}$.

The catalytic activity of GPx studied by several authors has shown no change ${ }^{(29)}$ or reduced levels of this enzyme between NASH subjects and the healthy controls ${ }^{(6,11,20)}$. The levels of GPx were also found to have no statistical difference $^{(21)}$ or with increased levels when compared with Control Group $^{(37)}$. The possible reasons for such modifications still need to be elucidated ${ }^{(6)}$. It is believed that the reduction in this enzyme activity may occur due to its depletion or inactivation by ROS, since oxidative damage to cellular membranes and hemoglobin are associated with the decreased activity of $\mathrm{GPX}^{(11)}$

Earlier studies have shown decreased levels of serum catalase between NASH and Control individuals ${ }^{(2,11,47)}$. However, another study has found no documented association in this serum activity ${ }^{(37)}$. The possible impairment of this enzyme in obesity could explain the absence of statistical difference between the NASH and Non-NASH Groups.

Studies have reported elevated levels of 8-isoprostane in NAFLD ${ }^{(22)}$ and NASH Groups ${ }^{(17,21)}$ when compared to eutrophic individuals. It was stated that there is a positive correlation between plasma 8-isoprostane, adipose tissue and insulin resistance. Another association was found with BMI, suggesting that lipid peroxidation in NAFLD could be related to the severity of obesity ${ }^{(46)}$. This positive association of 8-isoprostane with obesity, insulin resistance and dyslipidemia could explain the lack of significant difference between the groups in the present study.

Perlemuter and colleagues ${ }^{(37)}$ found no significant differ- ence in vitamin E levels between NAFLD and the Control Groups. Other published papers have shown significant decreased levels of vitamin E when comparing NASH Group with the control subjects ${ }^{(13)}$ and also with animal models ${ }^{(2)}$. The levels of vitamin $\mathrm{C}$ were also described as reduced in NASH animal models ${ }^{(2)}$. Some feasible causes to the lack of significant differences in the level of these vitamins can be discussed, such as, the depletion of the antioxidant reserves as a consequence of the oxidative stress, or even a low intake of the vitamin, in both groups ${ }^{(13)}$. Another explanation would be that the antioxidant status in the plasma may not reflect the oxidative status in the liver ${ }^{(37)}$.

The present study has some methodological limitations, such as, the impossibility to perform liver biopsy in the Non-NASH Group and the use of small sample sizes in both groups.

Yesilova et al. ${ }^{(47)}$ have suggested that the alterations in BMI, lipid metabolism and body fat may lead to changes in the oxidative status in NAFLD. Another assumption could be the possibility of insulin resistance being related to the decreased levels of antioxidants and lipid peroxidation products $^{(47)}$. Both hypothesis act in agreement with the similarity of oxidative stress found between the studied groups.

In conclusion, this paper demonstrates that only the presence of obesity is not enough to trigger alterations in all the studied biomarkers. We can not deny that obesity represents a major factor in the pathology of NASH and it contributes or perhaps, it could even be decisive to the presence of both the metabolic abnormailties as well as some altered OS markers. But, at the same time, the presence of NASH still represents the key for modifications in hepatic enzymes and some metabolic biomarkers, like glucose. Despite the majority of OS markers being found to be similar in both conditions, the NASH subjects could be slightly more affected than the Non-NASH individuals. Future studies selecting metabolically compatible individuals and larger sample sizes are needed to further elucidate this association.

\section{ACKNOWLEDGMENTS}

Financial support from Fapesp (Fundação de Amparo à Pesquisa do Estado de São Paulo) is acknowledged. We are grateful to Mrs. Maria Aparecida Nunes Ferreira and to Mrs. Mônica Silva de Souza Meirelles for assistance during biochemical analysis.

\section{Authors' contributions}

Leghi GE: conception and design of the study; data collection and study execution; statistical analysis and interpretation of the data; writing manuscript. Domenici FA: conception and design of the study and interpretation of the data; drafting the study and revising it critically for important intellectual content; statistical analysis; final approval of the version to be published. Vannucchi H: conception and design of the study and interpretation of the data; drafting the study and revising it critically for important intellectual content; statistical analysis; final approval of the version to be published. 
Leghi GE, Domenici FA, Vannucchi H. Influência do estresse oxidativo e obesidade em pacientes com esteatohepatite não alcoólica. Arq Gastroenterol. 2015,52(3):228-33.

RESUMO - Contexto - Esteatohepatite não alcoólica é considerada uma manifestação hepática da síndrome metabólica e está particularmente associada com a resistência insulínica, hipertensão, obesidade, anormalidades no metabolismo lipídico e da glicose. Objetivo - Considerando a importância da obesidade e do estresse oxidativo na fisiopatogenia da esteatohepatite não alcoólica, o objetivo deste estudo foi avaliar a associação e presença da obesidade e do estresse oxidativo nesta patologia. Métodos - Quinze pacientes com esteatohepatite não alcoólica (grupo esteatohepatite não alcoólica), diagnosticados de acordo com os achados histopatológicos da biópsia hepática, e 15 indivíduos sem esteatohepatite não alcoólica com sobrepeso/ obesidade (grupo sem esteatohepatite não alcoólica) foram incluídos. Todos os voluntários eram acompanhados em Hospital Universitário Brasileiro. Avaliação nutricional (peso, altura, índice de massa corporal e circunferência abdominal) e bioquímica (glicemia de jejum, enzimas hepáticas, lipidograma, leptina, superóxido dismutase, glutationa peroxidase, vitaminas $\mathrm{C}$ e E, catalase e 8-isoprostano) foram realizadas em todos os indivíduos. O teste $t$ de Student foi usado para análise estatística considerando o $P \leq 0,05$ como significativo. Resultados - Indivíduos do Grupo esteatohepatite não alcoólica apresentaram valores significativamente maiores de glicemia, AST, ALT, Gama GT, fosfatase alcalina, triglicérides e superóxido dismutase e menor valor de glutationa peroxidase, quando comparados ao Grupo sem esteatohepatite não alcoólica. Conclusão - Este artigo demonstra que somente a presença da obesidade não é suficiente para provocar alterações nos biomarcadores estudados. Apesar da maioria dos marcadores de estresse oxidativo apresentarem-se similar nas duas condições, os pacientes com esteatohepatite não alcoólica podem apresentar-se levemente mais afetados que os indivíduos sem esteatohepatite não alcoólica.

DESCRITORES - Hepatopatia gordurosa não alcoólica. Obesidade. Síndrome x metabólica. Estresse oxidativo. Marcadores biológicos.

\section{REFERENCES}

1. Adams LA, Lymp JF, St Sauver J, Sanderson SO, Lindor KD, Feldstein A, Angulo P. The natural history of nonalcoholic fatty liver disease: a population-based cohort study. Gastroenterology. 2005;129(1):113-21.

2. Amini R, Nosrati N, Yazdanparast R, Molaei M. Teucrium polium in prevention of steatohepatitis in rats. Liver Int. 2009;29(8):1216-21.

3. Angulo P. Nonalcoholic Fatty Liver Disease. N Engl J Med. 2002;346(16):1221-9.

4. Anstee QM, Goldin RD. Mouse models in non-alcoholic fatty liver disease and steatohepatitis research. Int J Exp Path. 2004;87(1):1-16.

5. Arnauld J, Fortis I, Blachier S, Kia D, Favier A. Simultaneous determination of retinol, $\alpha$-tocopherol and $\beta$-carotene in serum by isocratic high-performance liquid chromatography. J Chromatogr 1991;572(1-2):103-16.

6. Baskol G, Baskol M, Kocer D. Oxidative stress and antioxidant defenses in serum of patients with non-alcoholic steatohepatitis. Clin Biochem. 2007;40(11):776-80.

7. Brunt EM, Kleiner DE, Wilson LA, Belt P, Neuschwander-Tetri BA. Nonalcoholic fatty liver disease (NAFLD) Activity score and the histopathologic diagnosis in NAFLD: Distinct clinicopathologic meanings.Hepatology. 2011;53 (3): $810-20$

8. Clark JM, Diehl AM. Defining nonalcoholic fatty liver disease: implications for epidemiologic studies. Gastroenterology. 2003;124(1):248-50.

9. Comporti M, Arezzini B, Signorini C, Sgherri C, Monaco B, Gardi C. F2-isoprostanes stimulate collagen synthesis in activated hepatic stellate cells: a link with liver fibrosis? Lab Invest. 2005;85(11):1381-91.

10. Cuppari L. Guia de Medicina Ambulatorial e Hospitalar: Nutrição Clínica no Adulto Manole. Barueri; 2006.

11. Das SK, Balakrishnan V, Mukherjee S, Vasudevan DM. Evaluation of blood oxidative stress-related parameters in alcoholic liver disease and non-alcoholic fatty liver disease. Scand J Clin Lab Invest. 2008;68(4):323-34.

12. Day CP, James O. Steatohepatitis: a tale of two "hits"? Gastroenterology 1998, 114(4):842-5.

13. Erhardt A, Stahl W, Sies H, Lirussi F, Donner A, Häussinger D. Plasma levels of vitamin e and carotenoids are decreased in patients with nonalcoholic steatohepatitis (NASH). EurJ Med Res. 2011;16(2):76-8.

14. Flohé L, Guntzler WA. Assays of glutathione peroxidase. Methods Enzymol. 1984;105:115-21.

15. Friedewald WT, Levy RI, Fredrickson DS. Estimation of the concentration of low-density lipoprotein cholesterol in plasma, without use of the preparative ultracentrifuge. Clin. Chem. 1972;18(6):499-502.

16. Halliwell B, Lee CY. Using isoprostanes as biomarkers of oxidative stress: some rarely considered issues. Antioxid Redox Signal. 2010;13(2):45-56.

17. Haukeland JW, Damås JK, Konopski Z, Løberg EM, Haaland T, Goverud I, et al. Systemic inflammation in nonalcoholic fatty liver disease is characterized by elevated levels of CCL2. J Hepatol. 2006;44(6):1167-1174.
18. Hindle AK, Edwards C, Mendonsa A, et al. Adiponectin but not leptin is involved in early hepatic disease in morbidly obese patients. Surg Endosc 2010;24 (6): $1547-51$.

19. Johansson LH, Borg LA. A spectrophotometric method for determination of catalase activity in small tissue samples. Anal Biochem. 1988;174(1):331-6.

20. Koek GH, Liedorp PR, Bast A. The role of oxidative stress in non-alcoholic steatohepatitis. Clin Chim Acta. 2011;412(15-16):297-305.

21. Kojima H, Sakurai S, Uemura M, Fukui H, Morimoto H, Tamagawa T. Mitochondrial abnormality and oxidative stress in nonalcoholic steatohepatitis. Alcohol Clin Exp Res. 2007;31(1 Suppl):S61-6.

22. Konishi M, Iwasa M, Araki J, Kobayashi Y, Katsuki A, Sumida Y, et al. Increased lipid peroxidation in patients with non-alcoholic fatty liver disease and chronic hepatitis $\mathrm{C}$ as measured by the plasma level of 8 -isoprostane. J Gastroenterol Hepatol 2006;21(12):1821-5.

23. Kono Y, Fridovich I. Superoxide radical inhibits catalase. J Biol Chem. 1982;257(10):5751-4

24. Kopec KL, Burns D. Nonalcoholic Fatty liver disease: a review of the spectrum of disease, diagnosis, and therapy. Nutr Clin Pract. 2011;26(5):565.

25. Koppe SWP, Sahai A; Malladi P; Whitington PF. Green RM. Pentoxifylline attenuates steatohepatitis induced by the methionine choline deficient diet. J Hepatol. 2004;41(4):592-8.

26. Lam B, Younossi Z: Novel treatment strategies for patients with nonalcoholic fatty liver disease. Clin Invest 2011;1:229-239.

27. Lomonaco R, Sunny NE, Bril F, Cusi K. Nonalcoholic fatty liver disease: current issues and novel treatment approaches. Drugs. 2013;73(1):1-14.

28. Machado MV, Coutinho J, Carepa F, Costa A, Proença H, Cortez-Pinto H. How adiponectin, leptin, and ghrelin orchestrate together and correlate with the severity of nonalcoholic fatty liver disease. Eur J Gastroenterol Hepatol. 2012;24(10): 1166-72.

29. Machado MV, Ravasco P, Jesus L, Marques-Vidal P, Oliveira CR, Proença T, et al. Blood oxidative stress markers in non-alcoholic steatohepatitis and how it correlates with diet. Scand J Gastroenterol. 2008;43(1):95-102.

30. Marchesini G, Bugianesi E, Forlani G, Cerrelli F, Lenzi M, Manini R, et al. Nonalcoholic fatty liver, steatohepatitis, and the metabolic syndrome. Hepatology. 2003;37(4):917-23.

31. Mc Cord JM, Fridovich I. Superoxide dismutase. Anenzymic function for erythrocuprein (hemocuprein). J Biol Chem. 1969;244(22):6049-55.

32. Muriel P. Role of free radicals in liver diseases. Hepatol Int. 2009;3(4):526-36.

33. Musso G, Gambino R, Durazzo M, et al. Adipokines in NASH: postprandial lipid metabolism as a link between adiponectin and liver disease. Hepatology. 2005;42(5):1175-83.

34. Nigam P, Bhatt SP, Misra A, Vaidya M, Dasgupta J, Chadha DS. Non-alcoholic fatty liver disease is closely associated with sub-clinical inflammation: a case-control study on asian indians in North India. PLoS ONE. 2013;8(1):e49286. 
35. Nobili V, Alisi A, Raponi M. Pediatric non-alcoholic fatty liver disease: preventive and therapeutic value of lifestyle intervention. World J Gastroenterol. 2009;15(48):6017-22

36. Ogden CL, Carroll MD, Curtin LR, Mcdowell MA, Tabak CJ, Flegal KM. Prevalence of overweight and obesity in the United States, 1999-2004. JAMA 2006;295(13):1549-55.

37. Perlemuter G, Davit-Spraul A, Cosson C, Conti M, Bigorgne A, Paradis V, et al. Increase in liver antioxidant enzyme activities in non-alcoholic fatty liver disease. Liver Int. 2005;25(5):946-53

38. Pirgon Ö, Bilgin H, Cekmez F, Kurku H, Dündar BN. Association between insulin resistance and oxidative stress parameters in obese adolescents with non-alcoholic fatty liver disease. J Clin Res Pediatr Endocrinol. 2013;5(1):33-9.

39. Rolo AP, Teodoro JS, Palmeira CM. Role of oxidative stress in the pathogenesis of nonalcoholic steatohepatitis. Free Radic Biol Med. 2012;52(1):59-69.

40. Rose RC, Bode AM. Analysis of water-soluble antioxidants by high-pressure liquid chromatography. Biochem J. 1995;306(Pt 1):101-5.

41. Singal AK, Jampana SC, Weinman SA. Antioxidants as therapeutic agents for liver disease. Liver Int. 2011;31(10):1432-48

42. Starkel P, Sempoux C, Leclercq I, et al. Oxidative stress, KLF6 and transforming growth factor-beta up regulation differentiate non-alcoholic steatohepatitis progressing to fibrosis from uncomplicated steatosis in rats. J Hepatol. 2003;39(4):538-46.
43. Swellam M, Hamdy N. Association of nonalcoholic fatty liver disease with a singlenucleotide polymorphism on the gene encoding leptin receptor. IUBMB Life. 2012;64(2):180-6.

44. Timlin MT, Parks EJ. Temporal pattern of de novo lipogenes is in the postprandial state in healthy men. Am J Clin Nutr 2005;81(1):35-42.

45. Tsochatzis E, Papatheodoridis GV, Archimandritis AJ. The evolving role of leptin and adiponectin in chronic liver diseases. Am J Gastroenterol. 2006;101(11) 2629-40.

46. Urakawa H, Katsuki A, Sumida Y, Gabazza EC, Murashima S, Morioka K, et al. Oxidative stress is associated with adiposity and insulin resistance in men. J. Clin. Endocrinol. Metab. 2003;88(10):4673-6.

47. Yesilova Z, Yaman H, Oktenli C, et al. Systemic markers of lipid peroxidation and antioxidants in patients with nonalcoholic Fatty liver disease. Am J Gastroenterol 2005;100(4):850-5

48. Younossi ZM, Page S, Rafiq N, Birerdinc A, Stepanova M, Hossain N. A biomarker panel for non-alcoholic steatohepatitis (NASH) and NASH-related fibrosis. Obes Surg. 2011;21(4):431-9.

49. Zimmermann A, Zimmermann T, Schattenberg J, Pöttgen S, Lotz J, Rossmann H. Alterations in lipid, carbohydrate and iron metabolism in patients with non-alcoholic steatohepatitis (NASH) and metabolic syndrome. Eur J Intern Med. 2011;22(3):305-10. 